\title{
Segregation distortion of Brassica carinata derived black rot resistance in Brassica oleracea
}

\author{
Muhammet Tonguç ${ }^{1}$, Elizabeth D. Earle ${ }^{2}$ \& Phillip D. Griffiths ${ }^{1, *}$ \\ ${ }^{1}$ Department of Horticultural Sciences, Cornell University NYSAES, Geneva, N.Y. 14456, U.S.A.; ${ }^{2}$ Department of \\ Plant Breeding, Cornell University, 514 Bradfield Hall Ithaca, N.Y. 14853, U.S.A.; (*author for correspondence, \\ e-mail:pdg8@cornell.edu)
}

Received 1 April 2003; accepted 20 August 2003

Key words: cabbage, Ethiopian mustard, RAPD, Xanthomonas campestris

\section{Summary}

Three segregating $F_{2}$ populations were developed by self-pollinating 3 black rot resistant $F_{1}$ plants, derived from a cross between black rot resistant parent line 11B-1-12 and the susceptible cauliflower cultivar 'Snow Ball'. Plants were wound inoculated using 4 isolates of Xanthomonas campestris pv. campestris (Xcc) race 4 , and disease severity ratings of $F_{2}$ plants from the three populations were scored. A total of 860 arbitrary oligonucleotide primers were used to amplify DNA from black rot resistant and susceptible $F_{2}$ plants and bulks. Eight RAPD markers amplified fragments associated with completely disease free plants following black rot inoculation, which segregated in frequencies far lower than expected. Segregation of markers with black rot resistance indicates that a single, dominant major gene controls black rot resistance in these plants. Stability of this black rot resistance gene in populations derived from 11B-1-12 may complicate introgression into B. oleracea genotypes for hybrid production.

\section{Introduction}

Black rot is a bacterial disease of Brassica oleracea L. caused by Xanthomonas campestris pv. campestris (Xcc). Under natural conditions Xcc infects through hydathodes, moves through the midrib veins of the leaf and clogs vessels with polysaccharides producing Vshaped legions associated with the disease (Cook et al., 1952).

Black rot resistance is particularly important in the Brassica vegetables (B. oleracea) from which several accessions and varieties have been identified as resistant (Bain, 1952; Hunter et al., 1987). However, $B$. oleracea derived resistance is incomplete and controlled by quantitative trait loci (Camargo et al., 1995; Vicente et al., 2002). For effective hybrid production simple genetic control of resistance is desirable. Resistance has been identified in related Brassica species (Guo et al., 1991; Westman et al., 1999; Taylor et al., 2002; Tonguç \& Griffiths, 2003) including B. carinata accession PI 199947 (previously identified as B. napus
PI 199947). Black rot resistance derived from the accession has been associated with a single dominant gene, Xca 1 (Guo et al., 1991; Taylor et al., 2002; Vicente et al., 2002).

Related Brassica species can be used to introgress disease resistance and other agronomic and horticultural traits into $B$. oleracea even though chromosome numbers differ. This is due to high tolerance of aneuploidy and common ancestry in diploids. Resistance identified from PI 199947 was used to transfer black rot resistance to $B$. oleracea by protoplast fusion with a rapid-cycling $B$. oleracea followed by backcrosses to B. oleracea (Hansen \& Earle, 1995; Earle, 1997). Marker studies were previously undertaken with segregating populations derived from resistant somatic hybrids. Reciprocal backcross populations were used to study inheritance of the introgressed chromosomal fragment and to identify molecular markers linked to black rot resistance (Zhou et al., 1997). The proportion of resistant plants was significantly lower than expected for backcross generations and five linked markers 
were found. It was suggested that aneuploidy was the cause of distorted segregation, and repeated backrosses would eliminate extra chromosomal fragments and stabilize the transmission of the resistance.

Molecular markers provide a useful tool for plant breeders to identify resistance genes, and correlate their presence with disease severity symptoms following inoculation. Randomly amplified polymorphic DNA (RAPD) markers utilize random pieces of genomic DNA to create polymorphisms (Williams et al., 1990), and have been used to identify a number of disease resistance genes in different crop species such as pea (Tiwari et al., 1998) and broccoli (Giovannelli et al., 2002).

When evaluating germplasm for resistance to black rot, the race specificity of the resistance becomes very important. Six races of Xcc have been identified, and races 1 and 4 have been found to be the most common races worldwide (Vicente et al., 2001). Resistance to the most common races appeared to be present in several B-genome Brassicas including B. carinata. Resistance derived from PI 199947 provides complete protection against races 1 and 4 of Xcc following wound inoculation (Taylor et al., 2002; Vicente et al., 2002).

The aim of the current study was to identify RAPD markers associated with black rot resistance in $B$. oleracea breeding lines derived from $B$. carinata accession PI 199947 and evaluate their segregation in $F_{2}$ populations relative to disease symptoms.

\section{Materials and methods}

\section{Plant material}

The breeding line 11B-1-12 (Figure 1) was derived from protoplast fusion between susceptible rapidcycling $B$. oleracea and a resistant $B$. carinata accession PI 199947, followed by a backcross of a resistant somatic hybrid to white-flowered broccoli (Hansen \& Earle, 1995). Additional generations of backrosses and selfs produced line 11B-1-12 (Ren \& Earle, unpublished data). Resistant $F_{1}$ hybrids were selected following hybridization with the black rot susceptible cauliflower cultivar 'Snow Ball' and self-pollinated to produce segregating $F_{2}$ populations. Plants from 3 $F_{2}$ populations that segregated resistant plants along with cauliflower controls ('Snow Ball' and 'Delira'), cabbage controls ('Atlantis' and 'Bartolo') and broccoli controls ('Marathon' and 'Titleist') were grown
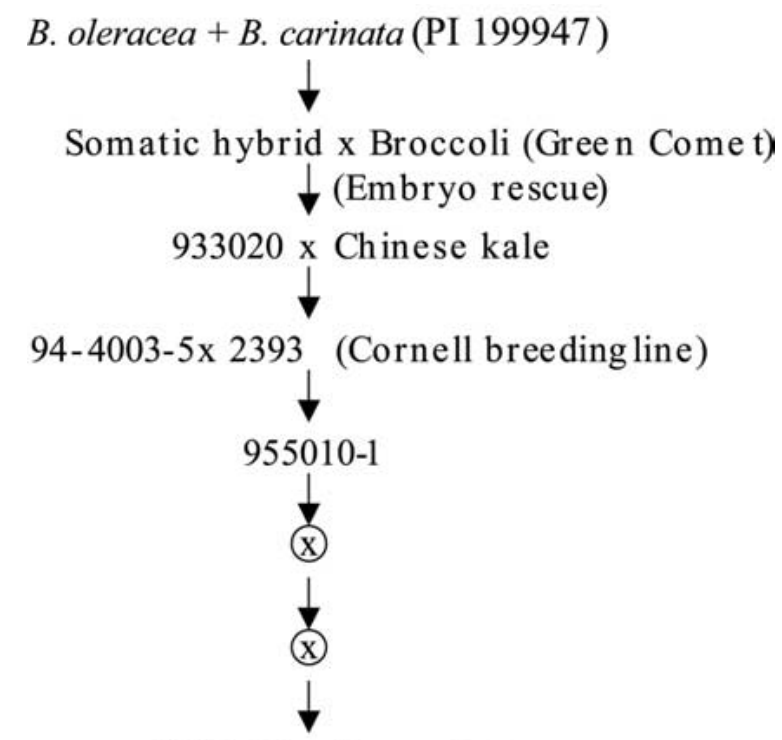

11B-1-12 x Snow Ball

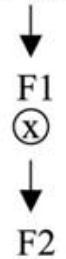

Figure 1. Generation of segregating $\mathrm{F}_{2}$ populations and pedigree of the resistant parent.

in plastic pots $(10 \mathrm{~cm}$ diameter) containing 'Cornell mix' (Boodley \& Sheldrake, 1982) in a greenhouse. Plants were grown at $23 / 20^{\circ} \mathrm{C}$ day/ night with a $14 \mathrm{~h}$ photoperiod under $1000 \mathrm{~W}$ metal halide lamps.

\section{DNA isolation}

Genomic DNA was isolated from the first true leaf according to Doyle \& Doyle (1990). Extracted DNA was quantified with a ThermoSpectronic spectrophotometer (BioMate, Pittsford, N.Y.) and final concentration of DNA was adjusted to $40 \mathrm{ng} / \mu \mathrm{l}$.

\section{Plant inoculations}

Plants were inoculated twice; first at 21 days, and the second at the 56 days using four race 4 Xcc isolates, obtained from D. Reed (Reeds Seeds, Cortland, N.Y.). Isolates were grown on YDCP medium (Shelton \& Hunter, 1985) for 2 days and used to wound inoculate the $F_{2}$ populations and control plants. The wound inoculation was performed by dipping 2 needles into bacteria and piercing a true leaf with infected needles 
Table 1. Disease severity rating scale of Xcc 14 days after wound inoculation

\begin{tabular}{ll}
\hline Disease rating & Symptoms \\
\hline 1 & No symptoms \\
2 & Minimal symptom development from the point of infection \\
3 & Development of symptoms up to $1 \mathrm{~cm}^{2}$ from the point of infection \\
4 & Symptom development extending to leaf margins \\
5 & Symptom development along leaf margins followed by leaf abscission \\
\hline
\end{tabular}

Table 2. RAPD markers linked to black rot resistance, their sequences and the sizes of the linked fragments

\begin{tabular}{llc}
\hline Primer name & Primer sequence (5'-3') & Fragment size (bp) \\
\hline OPAB04 & GGCACGCGTT & 575 \\
UBC 72 & GAGCACGGGA & 1500 \\
UBC 322 & GCCGCTACTA & 400 \\
UBC 66 & GAGGGCGTGA & 500 \\
UBC 205 & CGGTTTGGAA & 900 \\
UBC 121 & ATACAGGGAG & 360 \\
UBC 320 & CCGGCATAGA & 450 \\
UBC 327 & ATACGGCGTC & 300 \\
\hline
\end{tabular}

on either side of the midrib. All four isolates were used to inoculate leaves of the same plants. Plants were rated after 35 days and diseased leaves were removed. Plants were allowed to develop new leaves for 21 days prior to re-inoculation at 56 days and at a second rating at 70 days. After the each inoculation all plants were placed in a $100 \%$ humidity mist chamber for 48 $\mathrm{h}$ at $20{ }^{\circ} \mathrm{C}$. Plants were rated according to Table 1 , and plants with a rating of 1 were considered to be completely resistant.

\section{Nuclear DNA content}

Estimation of nuclear DNA content was conducted with a flow cytometry, EPICS Profile Analyzer (Coultier Electronics, Hialeah, Fla.). Samples and standards were prepared and analyzed as described in Arumuganathan \& Earle (1991).

\section{RAPD analysis}

DNA bulks (Michelmore et al., 1991) were prepared from 8 symptomless and 10 completely susceptible plants following inoculation with black rot in a segregating $\mathrm{F}_{2}$ population. Arbitrary 10-mer oligonucleotide primers from Operon Technologies Inc., (Alameda,
Calif.) and University of British Columbia (Vancouver, B.C., Canada) were used to amplify DNA to identify RAPD markers associated with symptomless plants (Williams et al., 1990). Each reaction consisted of $8 \mu \mathrm{l}$ of sterile $\mathrm{dH}_{2} \mathrm{O}, 4 \mu \mathrm{l}$ of $5 \mathrm{X}$ PCR buffer $(0.5 \mathrm{M}$ Tris, $\mathrm{pH} 8.3,10 \mathrm{mM} \mathrm{MgCl} 2,10 \mathrm{mM}$ Tartrazine, $14 \%$ w/v Ficoll), $2 \mu \mathrm{l}$ of genomic DNA, $2 \mu \mathrm{l}$ of $0.13 \mathrm{mM}$ of each of the dNTPs, $2 \mu \mathrm{l}$ of $0.1 \mathrm{mM}$ primer and $2 \mu \mathrm{l}$ of $\mathrm{Taq}$ polymerase. One drop of mineral oil was added to the top of each well. PCR reactions were performed using a RoboCycler ${ }^{\circledR}$ thermalcycler (Stratagene, La Jolla, Calif.). The PCR cycle parameters were 40 cycles of $1 \mathrm{~min}$ denaturation at $94^{\circ} \mathrm{C}, 1.5$ min annealing at $35^{\circ} \mathrm{C}$ and 2 min extension at $72{ }^{\circ} \mathrm{C}$. PCR products were separated by gel electrophoresis in $1.5 \%$ agarose gels. Electrophoresis was performed in IX TAE buffer for $70 \mathrm{~min}$ at $83 \mathrm{~V}$ (constant voltage). Gels were stained with ethidium bromide and visualized under UV light with a Gel Doc 2000 system and pictures were digitally recorded with 'Quantity One' software (Bio-Rad Lab., Hercules, Calif.).

\section{Statistical analysis}

Association between markers and disease ratings were calculated with Gamma $(\gamma)$ statistics (Agresti, 1984).

$$
\begin{aligned}
& \gamma=\mathrm{C}-\mathrm{D} / \mathrm{C}+\mathrm{D}, \\
& \text { where } C=\sum_{i<k} \sum_{j<l} n_{i j} n_{k l} \\
& \text { and } D=\sum_{i<k} \sum_{j>l} n_{i j} n_{k l} .
\end{aligned}
$$

$C$ and $D$ are the sum of all of the pairwise products of the cells, $i=$ the number of individuals with presence or absence of the markers with a marker score of $j$, and $k$ and $l$ are the ordered variables defining rows and columns of a cell.

Recombination frequencies were calculated with the formulae: $r=R / N$, where $r=$ recombination fre- 

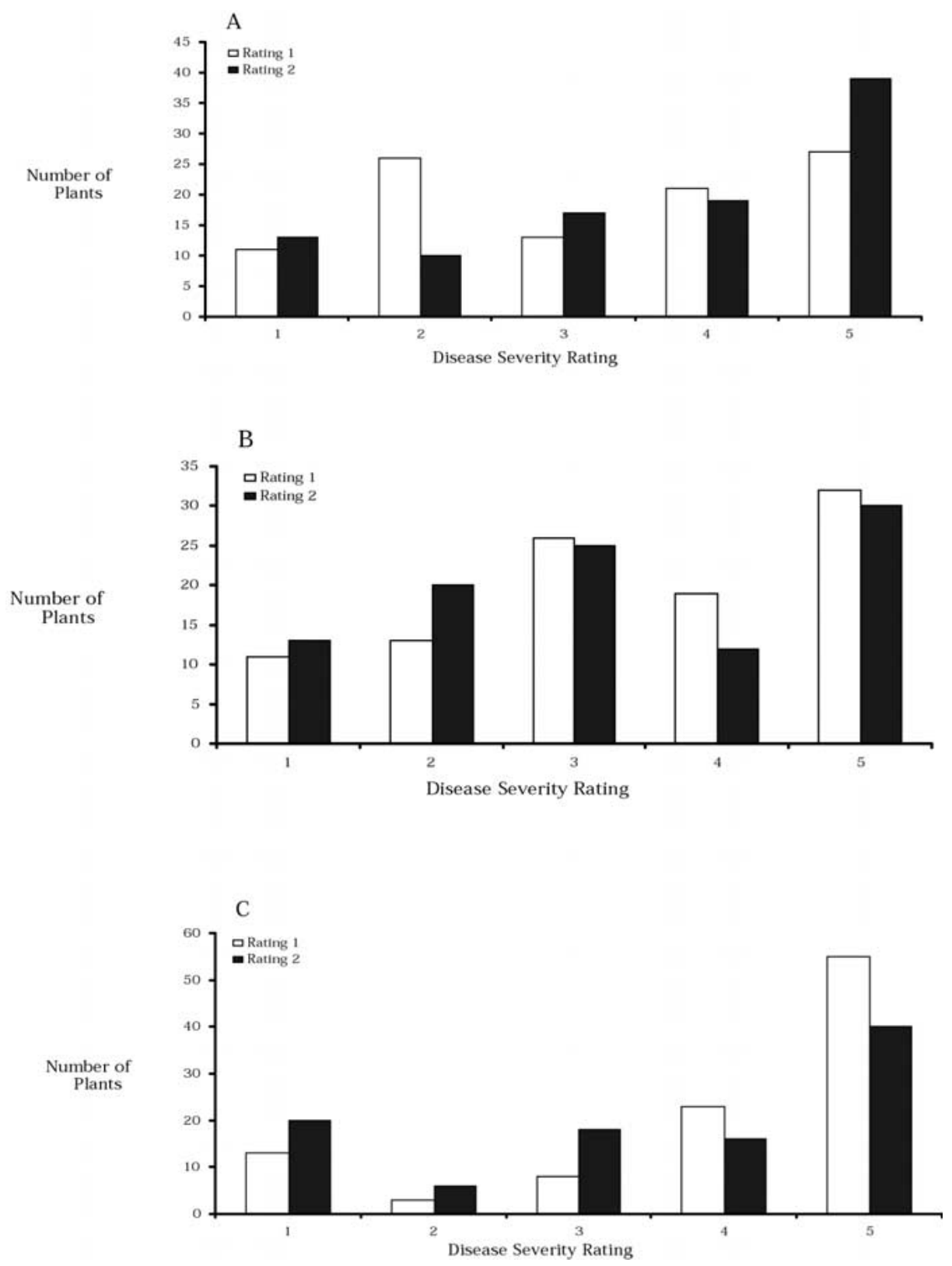

Figure 2. Disease severity ratings for black rot inoculated plants in populations P1 (A), P2 (B) and P3 (C).

quency, $\mathrm{R}=$ number of recombinants, and $\mathrm{N}=$ total number of individuals tested. The standard error of recombination frequency was estimated as $\mathrm{SE}_{\mathrm{r}}=[\mathrm{r}(1-$ $\mathrm{r}) / \mathrm{N}]^{1 / 2}$ (Adams \& Joly, 1980). Mendelian segregation of resistance was investigated with the chi-square goodness-of-fit test.

\section{Results}

The majority of plants from the parent line 11B-1-12 were symptomless when needle inoculated; however, some plants were susceptible. The same susceptibility was also observed in some $F_{1}$ plants derived from resistant 11B-1-12 parent plants suggesting that the resistance was heterozygous and/or not stable in the $F_{1}$ progeny. Three resistant $F_{1}$ plants were chosen and 
Table 3. Association of RAPD markers with black rot resistant as measured using $\gamma$.statistics

\begin{tabular}{|c|c|c|c|c|c|c|}
\hline & \multicolumn{2}{|l|}{$\mathrm{P} 1$} & \multicolumn{2}{|l|}{$\mathrm{P} 2$} & \multicolumn{2}{|l|}{$\mathrm{P} 3$} \\
\hline & Rating 1 & Rating 2 & Rating 1 & Rating 2 & Rating 1 & Rating 2 \\
\hline OPAB04 & $0.78^{* * *}$ & $0.88 * * *$ & $0.89^{* * *}$ & $0.95^{* * *}$ & $1.0 * * *$ & 1.0 *** \\
\hline UBC 72 & $0.87^{* * *}$ & $1.0 * * *$ & $1.0 * * *$ & $1.0 * * *$ & $0.91^{* * *}$ & $0.86^{* * *}$ \\
\hline UBC 322 & $0.88^{* * *}$ & $1.0 * * *$ & $1.0 * * *$ & $1.0^{* * *}$ & $1.0^{* * *} 1.0 * * *$ & \\
\hline UBC 66 & $0.87^{* * *}$ & $1.0 * * *$ & $1.0 * * *$ & 1.0 *** & $0.91 * * *$ & $0.86^{* * *}$ \\
\hline UBC 205 & $0.88^{* * *}$ & $1.0 * * *$ & $1.0 * * *$ & $1.0 * * *$ & 0.82 *** & $0.74 * * *$ \\
\hline UBC 121 & $0.88 * * *$ & $1.0 * * *$ & $1.0 * * *$ & $1.0 * * *$ & $0.91 * * *$ & $0.86^{* * *}$ \\
\hline UBC 320 & $0.88 * * *$ & $1.0 * * *$ & ND & ND & ND & ND \\
\hline UBC 327 & $0.92 * * *$ & $1.0 * * *$ & $1.0 * * *$ & $0.69 * *$ & $1.0 * * *$ & $1.0 * * *$ \\
\hline
\end{tabular}

** significant at $p=0.01$, and $* * *$ significant at $p=0.001$, respectively.

$\mathrm{ND}=$ No segregation of the marker.

Table 4. Recombination frequencies between RAPD markers and black rot resistance in populations $\mathrm{P} 1, \mathrm{P} 2$ and $\mathrm{P} 3$, and $\chi^{2}$-values for the deviation from the expected segregation ratio of $3: 1$

\begin{tabular}{|c|c|c|c|c|c|c|}
\hline & \multicolumn{2}{|l|}{$\mathrm{P} 1$} & \multicolumn{2}{|l|}{$\mathrm{P} 2$} & \multicolumn{2}{|l|}{ P3 } \\
\hline & $\mathrm{r} \pm \mathrm{SE}(\mathrm{cM})$ & $x^{2}$ & $\mathrm{r} \pm \mathrm{SE}(\mathrm{cM})$ & $x^{2}$ & $\mathrm{r} \pm \mathrm{SE}(\mathrm{cM})$ & $x^{2}$ \\
\hline OPAB04 & $7 \pm 2$ & $205.0^{* * *}$ & $3 \pm 2$ & $232.3^{* * *}$ & 0.0 & $232.2^{* * *}$ \\
\hline UBC 72 & $3 \pm 2$ & $205.0^{* * *}$ & $0.0225 .3^{* * *}$ & $1 \pm 0.09$ & $218.6^{* * *}$ & \\
\hline UBC 322 & $4 \pm 2$ & $205.0^{* * *}$ & $0.0225 .3^{* * *}$ & $1 \pm 0.09$ & $225.4^{* * *}$ & \\
\hline UBC 66 & $3 \pm 2$ & $93.0^{* * *}$ & $0.0225 .3^{* * *}$ & $1 \pm 0.09$ & $218.6^{* * *}$ & \\
\hline UBC 205 & $3 \pm 2$ & $93.0^{* * *}$ & $0.0225 .3^{* * *}$ & $2 \pm 1$ & $211.8^{* * *}$ & \\
\hline UBC 121 & $3 \pm 2$ & $93.0^{* * *}$ & $0.0225 .3^{* * *}$ & $1 \pm 0.09$ & $211.8^{* * *}$ & \\
\hline UBC 320 & $3 \pm 2$ & $93.0^{* * *}$ & ND & - & ND & - \\
\hline UBC 327 & $3 \pm 2$ & $205.0^{* * *}$ & $0.0225 .3^{* * *}$ & $5 \pm 3$ & $148.2^{* * *}$ & \\
\hline
\end{tabular}

*** significant at $p=0.001$.

$\mathrm{ND}=$ No segregation of the marker.

self-pollinated to produce 3 segregating $F_{2}$ populations (P1, P2, P3). The proportions of resistant plants in the $F_{2}$ populations significantly deviated from the 3:1 ratio, expected for a single dominant gene in an $\mathrm{F}_{2}$ population $\left[\mathrm{P} 1 \chi^{2}=201.7(p>0.001)\right.$, P2 $\chi^{2}=225.3(p>0.001)$ and P3 $\chi^{2}=239.0$ $(p>0.001)] . \mathrm{F}_{3}$ progeny derived from self pollinating $\mathrm{F}_{2}$ plants also failed to meet expected segregation ratios for a single dominant homozygous or heterozygous resistance gene, suggesting multiple gene control, pleiotropy or chromosomal instability causing segregation distortion from expected frequencies. Control cultivars were completely susceptible with slower disease development in broccoli cultivars. Plants initially rated 2-3 after 14 days (Figure 2) showed slower disease development, but were considered susceptible to black rot infection if disease symptoms were allowed additional time to develop.

Flow cytometry analysis was carried out to determine genome size in 11B-1-12. Standard 'Green Comet' has diploid nuclear DNA content of $1.3 \mathrm{pg}$. The diploid chromosome number of $B$. oleracea is 18 , and DNA content for an average $B$. oleracea chromosome is $0.07 \mathrm{pg}$. Flow cytometry analysis of resistant plants revealed that those plants also had DNA content of 1.3 $\mathrm{pg}$, which fell into the expected range for $2 \mathrm{n}=18$ (data not shown).

A total of 860 Operon and UBC primers were used screen resistant and susceptible bulks. RAPD primers produced 3 to 15 scoreable fragments with an average of 8.1 fragments per primer. 150 RAPD polymorphisms were identified between resistant and susceptible bulks and used to evaluate population P1. Twenty marker polymorphisms were identified in the P1 population. Of these polymorphisms 8 markers showed strong association with black rot resistance (Table 2). These markers were used to screen all populations, and significant associations between markers and the symptomless phenotype were calculated (Table 3). Recombination frequencies were estimated for resist- 


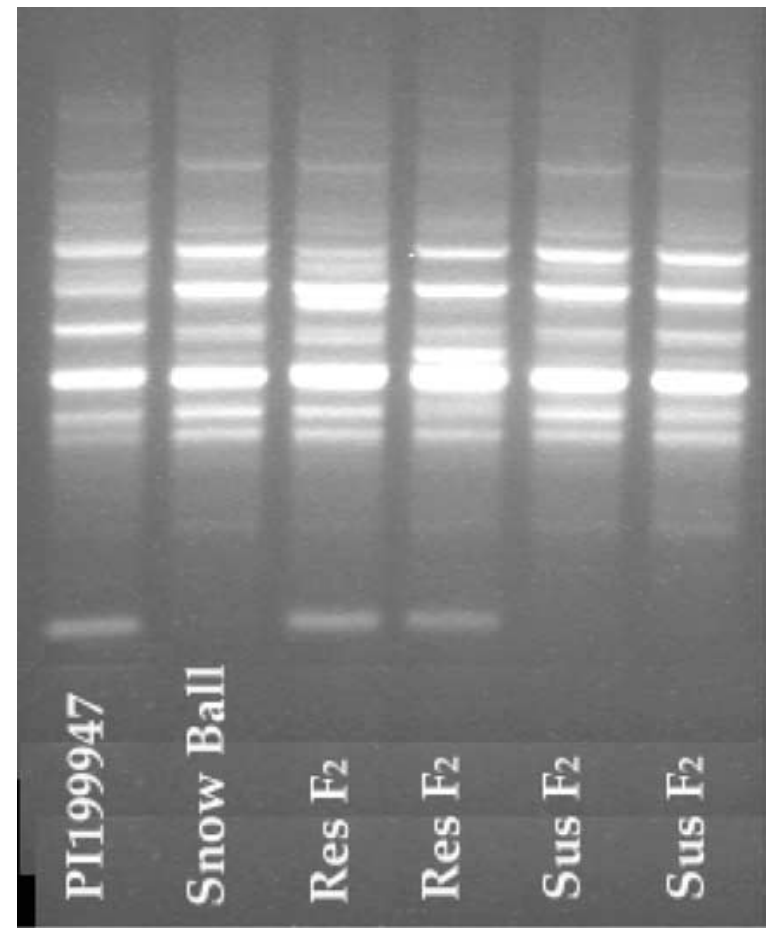

Figure 3. RAPD polymorphism generated by UBC 327 is inherited from B. carinata (PI 199947) in resistant plants in $F_{2}$ populations.

ant locus and for each marker in the three populations, as well as $\chi^{2}$-values (Table 4). All linked markers significantly deviated from the expected 3:1 ratio. All primers were used to amplify donor DNA, and we found that they also amplified the corresponding fragments in PI 199947 (Figure 3). All primers gave clear scoreable fragments in all populations. UBC $320 \mathrm{did}$ not produce any polymorphisms between resistant and susceptible individuals in the populations P2 and P3, and there were differences between the populations for the recombination frequencies of the linked markers. All markers segregated in P1; however, there was no recombination between the black rot resistance and six markers in P2. One marker (OPAB04) did not show any recombination in $\mathrm{P} 3$. The highest recombination frequency was observed for the marker OPAB04 in the population P1 (Table 4).

\section{Discussion}

The presence of dominant RAPD markers was associated with complete black rot resistance in wound inoculated seedlings. As with the disease severity ratings, the RAPD markers associated with black rot resistance showed extreme segregation distortion. This suggests that a single dominant resistant gene for black rot resistance is present in these segregating populations, but did not segregate in expected ratios. However it was not possible to confirm monogenic segregation of resistance in $\mathrm{F}_{2}$ populations due to a distorted segregation. Causes of segregation distortion could include: multiple gene control, pleitropy, gametic abortion, any chromosomal instability such as aneuploidy or an unstable translocation. The segregation distortion of RAPD markers linked to the resistance in $F_{2}$ populations provides strong evidence that multiple gene control, pleiotropy and aneuploidy are not responsible for the distortion of resistance as linked RAPD markers would have segregated in $75 \%$ of the $F_{2}$ progenies, although presence of a second gene, very closely linked to the $X c a 1$ in the genome of B. carinata, and/or minor genes are possible. Seed set was also normal indicating that gametes were stable and viable in these populations.

In a previous study Zhou et al. (1997) identified five RAPD primers linked to the black rot resistance; however, none of the reported markers were linked to black rot resistance in this study. Eight markers were linked to symptomless plants in these populations. Association of RAPD fragments and disease rating scores was highly significant (Table 3), and recombination frequencies were generally low. Different recombination frequencies were observed for linked RAPD markers in $\mathrm{F}_{2}$ populations (Table 4). All markers came from the resistant donor parent and therefore they amplify the B-genome of B. carinata. These results suggested that the introgressed genetic material from $B$. carinata might not be stable in $B$. oleracea genotypes.

Resistant plants grown to flowering in the greenhouse produced normal flowers and did not appear to exhibit gametic inviability. When they were self or cross-pollinated, plants produced normal seeds and formed full siliques. No bud pollination was necessary to produce selfed seeds, which suggested that black rot resistant plants were self-compatible. Irregular meiotic behavior might be present in resistant plants as a result of an unstable chromosome translocation that reduces the transmission of resistance in selfed and backcross generations.

Brassica species contain homologous segments within and between genomes resulting from extensive duplications of chromosomal segments and gene ordering (Kianian \& Quiros, 1992; Struss et al., 1996; Truco et al., 1996). The B and C Brassica genomes 
are moderately homologous (Truco et al., 1996), and it is possible to produce interspecific hybrids between Brassica species to transfer various traits into cultivated germplasm. In some populations derived from interspecific crosses it is difficult to obtain stable recombinant lines or the transferred resistance can be lost during backcross generations (Plieske et al., 1998). Similar transmission problems have been encountered with other species involving interspecific hybridizations (Heijbroek et al., 1988). One way to circumvent the problem is to obtain plants in which the chromosomal segment carrying the resistance gene of interest is translocated to a recurrent parent chromosome. This process would stabilize the introgressed segment of donor DNA and consequently populations would not exhibit segregation distortion (Heijbroek et al., 1988; Struss et al., 1996).

Loss of linked markers from a previous study (Zhou et al., 1997) suggests that the size of the introgressed segment in these populations is reduced. In the present study, loss of the linked fragment from UBC 320 in the populations P2 and P3 might also indicate that a chromosomal segment has been lost among resistant plants originated from two different $F_{1}$ plants. Different recombination rates were observed between the Xca 1 locus and linked markers in different populations. This result suggests that recombination between $\mathrm{B}$ and $\mathrm{C}$-genomes occurs but it was not sufficient to stabilize $\mathrm{B}$-genome derived resistance in a $\mathrm{C}$-genome background.

It will be necessary to stabilize this black rot resistance gene in B. oleracea genotypes for it to be used in commercial breeding. One approach could be to observe meiotic behavior of resistant plants and select plants with most regular meiosis to produce selfed and backcross generations (Heijbroek et al., 1988; Chévre et al., 1997). Another approach might be to order the RAPD markers relative to each other and the resistance locus and follow segregation or loss of RAPD markers in further generations. Radiation is known to cause chromosomal translocations in plants. Irradiation of seeds or floral parts has previously been used to stabilize foreign DNA in cultivated plants (Knott, 1968). It might be possible to use the same approach in $B$. oleracea plants carrying $B$. carinata chromosome segments to stabilize the transmission of the resistance locus.

\section{Acknowledgements}

We thank John Barnard for help in statistical analysis in this work, and Jian-ping Ren for the development of resistant parent used in this study. This work was supported by a scholarship for Muhammet Tonguç from the Turkish Ministry of Education and N.Y. State IPM Program.

\section{References}

Adams, W.T. \& R.J. Joly, 1980. Linkage relationships among twelve allozyme loci in loblolly pine. J Hered 1: 199-202.

Agresti, A., 1984. Analysis of Ordinary Data. Wiley, New York, N.Y.

Arumugunathan, K. \& E.D. Earle, 1991. Estimation of nuclear DNA content of plants by flow cytometry. Plant Mol Biol Rep 9: 229241.

Bain, D.C., 1952. Reaction of Brassica seedlings to black rot. Phytopathology 42: 497-500.

Boodley, J.W. \& R. Sheldrake. Jr., 1982. Cornell peat-lite mixes for commercial plant growing. New York Agr Exp Sta Agr Info Bul 43.

Camargo, L.E.A., P.H. Williams \& T.C. Osborn, 1995. Mapping of quantitative loci controlling resistance of Brassica oleracea to Xanthomonas campestris pv. campestris in the field and greenhouse. Phytopathology 85: 1296-1300.

Chévre, A.M., P. Barret, F. Eber, P. Dupuy, H. Brun, X. Tanguy \& M. Renard, 1997. Selection of stable Brassica napus-B. juncea recombinant lines resistant to black leg (Leptosphaeria maculans). 1. Identification of molecular markers, chromosomal and genomic origin of the introgression. Theor Appl Genet 95: 1104-1111.

Cook, A.A., J.C. Walker \& R.H. Larson, 1952. Studies on the disease cycle of black rot of crucifers. Phytopathology 42: $162-167$.

Doyle, J. \& J. Doyle, 1990. Isolation of plant DNA from fresh tissue. Focus 12: 13-15.

Earle, E.D., 1997. Crucifer vegetables with resistance to blackrot and Alternaria leaf spot. 1996 New York State Vegetable Project Reports Relating to IPM. NYS IPM Publication \#121, Cornell Cooperative Extension.

Giovannelli, J.L., M.W. Farnham, M. Wang \& A.E. Strand, 2002. Development of sequence characterized amplified region markers linked to downy mildew resistance in broccoli. J Amer Soc Hort Sci 127: 597-601.

Guo, H., M.H. Dickson \& J.E. Hunter, 1991. Brassica napus sources of resistance to black rot in crucifers and inheritance of resistance. HortScience 26: 1545-1547.

Hansen, L.N. \& E.D. Earle, 1995. Transfer of resistance to Xanthomonas campestris pv. campestris into Brassica oleracea L. by protoplast fusion. Theor Appl Genet 91: 1293-1300.

Heijbroek, W., A.J. Roelands, J.H. de Jong, C. van Hulst, A.H.L. Schoone \& R.G. Munning, 1988. Sugar beets homozygous for resistance to beet cyst nematode (Heterodera schachtii Schm.), developed from monosomic additions of Beta procumbens to $B$. vulgaris. Euphytica 38: 121-131.

Hunter, J.E., M.H. Dickson \& J.W. Ludwig, 1987. Sources of resistance to black rot of cabbage expressed in seedlings and adult plants. Plant Dis 71: 263-266. 
Kianian, S.F. \& C.F. Quiros, 1992. Generation of a Brassica oleracea composite map, linkage arrangements among various populations and evolutionary implications. Theor Appl Genet 84: 544-554.

Knott, D.R., 1968. Translocations involving Triticum chromosomes and Agropyron chromosomes carrying rust resistance. Can J Genet Cytol 10: 695-696.

Michelmore, R.W., I. Paran \& R.V. Kesseli, 1991. Identification of markers linked to disease resistance genes by bulked segregant analysis: a rapid method to detect markers in specific genomic regions by using segregating populations. Proc Natl Acad Sci USA 88: 9828-9832.

Plieske, J., D. Struss \& G. Röbbelen, 1998. Inheritance of resistance derived from the B-genome of Brassica against Phoma lingam in rapeseed and the development of molecular markers. Theor Appl Genet 97: 929-936.

Shelton, A.M. \& J.E. Hunter, 1985. Evaluation of the potential of the flea beetle Phyllotreta cruciferae to transmit Xanthomonas campestris pv. campestris, causal agent of black rot of crucifers. Can J Plant Path 7: 308-310.

Struss, D., C.F. Quiros, J. Plieske \& G. Röbbelen, 1996. Construction of Brassica B genome synteny groups based on chromosomes extracted from three different sources by phenotypic, isozyme and molecular markers. Theor Appl Genet 93: 10261032.

Taylor, J.D., J. Conway, S.J. Roberts, D. Astley \& J.G. Vicente, 2002. Sources and origin of resistance to Xanthomonas campestris pv. campestris in Brassica genomes. Phytopathology 92: $105-111$.
Tiwari, K.R., G.A. Penner \& T.D. Warkentin, 1998. Identification of coupling and repulsion phase RAPD markers for powdery mildew resistance gene $e r-1$ in pea. Genome 41: 440-444.

Tonguç, M. \& P.D. Griffiths, 2003. Evaluation of Brassica carinata accessions for resistance to black rot (Xanthomonas campestris pv. campestris). HortScience (in press).

Truco, M.J., J. Hu, J. Sadowski \& C.F. Quiros, 1996. Inter- and intra-genomic homology of the Brassica genomes: implications for their origin and evolution. Theor Appl Genet 93: 1225-1233.

Vicente, J.G., J. Conway, S.J. Roberts \& J.D. Taylor, 2001. Identification and origin of Xanthomonas campestris pv. campestris races and related pathovars. Phytopathology 91: 492-499.

Vicente, J.G., J.D. Taylor, A.G. Sharpe, I.A.P. Parkin, D.J. Lydiate \& G.J. King, 2002. Inheritance of race-specific resistance to Xanthomonas campestris pv. campestris in Brassica genomes. Phytopathology 92: 1134-1141.

Westman, A.L., S. Kresovich \& M.H. Dickson, 1999. Regional variation in Brassica nigra and other weedy crucifers for disease reaction to Alternaria brassicicola and Xanthomonas campestris pv. campestris. Euphytica 106: 253-259.

Williams, J.G.K., A.R. Kubelik, K.J. Livak, J.A. Rafalski \& S.V. Tingey, 1990. DNA polymorphisms amplified by arbitrary primers are useful as genetic markers. Nucleic Acids Res 18: 6531-6535.

Zhou, Z., N.F. Weeden \& M.H. Dickson, 1997. The expression of a resistant gene to black rot in progeny of the protoplast fusion broccoli (B. oleracea). Cruciferae Newsl 19: 109-110. 